\title{
Recent Advances in High-Power Industrial Applications
}

\author{
Leopoldo G. Franquelo, Jose I. Leon and Eugenio Dominguez \\ Electronic Engineering Department \\ University of Seville \\ Seville, Spain 41092 \\ Email: lgfranquelo@ieee.org
}

\begin{abstract}
The industrial electronics market is continuously changing following the users demand. This paper introduces the current industrial electronics applications and is focused in the medium-voltage high-power ones. The multilevel approach is the most attractive solution to achieve the challenges that medium voltage-high power applications arise. Several commercial examples are introduced and some of the last research advances related to multilevel power electronic converters are presented in this paper.
\end{abstract}

\section{INTRODUCTION}

Electronic devices are step by step more present in our life. Among the different electronic topics, power electronics is a discipline with very specific issues clearly different from other topics such as analog, digital or RF, where the main objective is to process an information. On the other hand, power electronic systems deal with the electric energy conversion. It is a relatively recent technology because its first steps can be dated in the mid 50's with the commercialization of the SCR. However, its effects on our lives are everyday more and more clear leading to an important reduction in economical cost, size and increase of performances of the energy systems [1]. The non-stop development of new and more efficient power semiconductors and the use of advanced control techniques, implemented in modern digital microprocessors, has made possible many of the desirable characteristics of modern power systems. Today important markets can be found in areas as diverse as: industrial, commercial, residential, transportation, utility, aerospace and military among others. One possible classification could be done taking into account three main scenarios and is presented in Table I, where the main applications, benefits of applying power electronics and the main requirements are presented.

The power rating for these scenarios can be ranged from small consumer applications (around watts) to the power grid applications where very high-power applications are needed (around hundreds of megawatts or even gigawatts). In this last group of high-power systems, power electronics plays a crucial role as provider of the technology to improve the efficiency and stability of the grid. This is achieved by optimally controlling the power flows in the electric distribution grid and, from the load side, saving the total energy that loads like large motors are consuming. In addition, nowadays other power electronic systems such as the Flexible AC Transmis- sion Systems (FACTS) and the High-Voltage Direct Current (HVDC) are being installed to increase the power distribution efficiency and the grid quality and stability. Another important issue for power electronic systems is the efficient integration of renewable energies to the electrical grid. Also, other promising application for the stability of the network is the capability of the electronics systems to allow the connection of energy storage systems. In this way, the excess of produced energy can be saved to be used when a peak in the power demand is present.

The modern structure of a power grid can be seen in Fig. 1 , where the different places where the power electronics systems can be employed are identified. This structure presents a high meshed network, high integration of renewable energies an and adequate connection between other grids. This new distribution grid concept solves the typical problems of the classical structure of the power grid by using power electronic converters. For instance, the renewable energies integration in the power grid has created a wide range of possible high-power applications for power electronic systems [2]. The current trend is forcing to develop higher-power systems, especially in wind energy and storage systems. In addition, FACTS converters are especially designed to improve the quality, the flexibility and the stability of the distribution grid. Other converters such as the HVDC is applied to distribute the energy using a dc connection what is especially interesting in the offshore wind energy applications.

\section{High-Power Industrial ApPliCATIONS}

\section{A. High-Power Semiconductors}

To implement very high-power electronics systems, high power devices are needed [3]. As mentioned before, the solid state power electronics era started about 50 years ago with the commercialization of the SCR. The evolution of power electronic devices has been constant during these years, but it can be mentioned two important milestones: the insulated gate bipolar transistor (IGBT) in the mid 80's and more recently the integrated gate-commutated thyristor (IGCT). These two devices are currently the workhorses for most of the industrial converters. In Fig. 2, some of the currently commercially available devices are shown. There has been an important evolution of these devices in the last decades, but the market driven applications are growing even faster in terms of the 


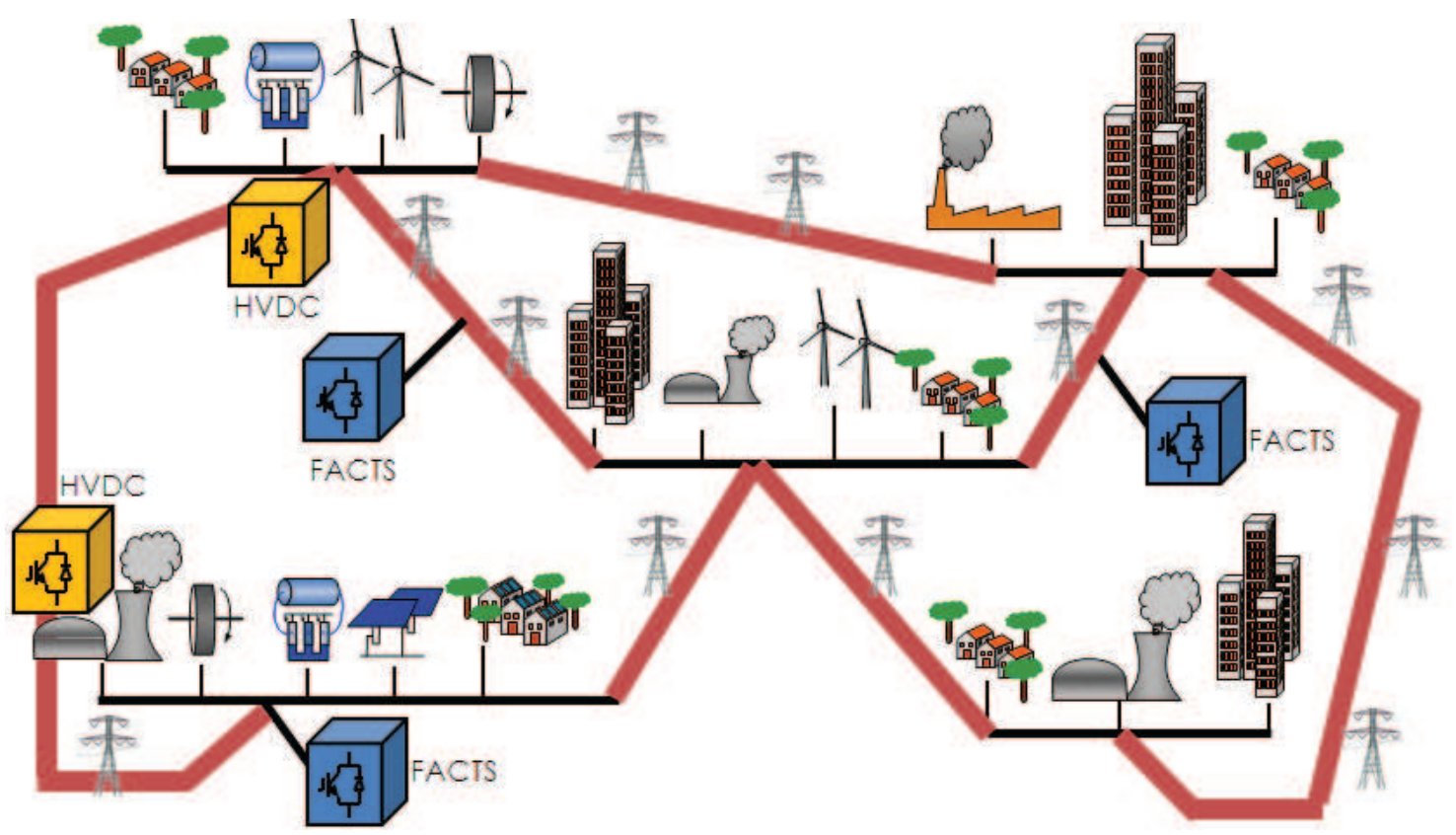

Fig. 1. Modern scenario of the electrical grid

rated power required, this opens a new niche for advanced topologies that can overcome this limitation or will take advantage of a more mature device technology that has been tested for years in industry.

\section{B. High-Power Converters Topologies. The Multilevel Con- verters}

The power converter for high-power applications can be built based on high-power semiconductors (for instace using $6.6 \mathrm{kV}$ IGCTs). However, since multilevel converters appear in the last decades of the 20th century, they are a very attractive solution due to their advantages in terms of high nominal power, low dv/dt's, low voltage stress of the power devices and high quality of the output waveforms [4]-[7]. In fact, in the last decade multilevel converters have become a commercial product for instance to integrate new renewable energy sources to the distribution grid [2]. As it was affirmed in [4], the age of multilevel converters has arrived. Among the multilevel converter topologies, the diode-clamped converter, also usually called neutral-point-clamped converter (NPC), the flying capacitor converter (FC) and the cascaded H-bridge converter (CHB) are the most common ones. A single-phase diagram of these three topologies is represented in Fig. 3.

The three-level NPC was introduced in 1981 and it is

TABLE I

MAIN APPLICATIONS, BENEFITS AND REQUIREMENTS OF POWER ELECTRONICS

\begin{tabular}{|c|c|c|c|}
\hline & Consumer Electronics & Automotive and Transport & Power grids and Industry \\
\hline Applications & $\begin{array}{l}\text { Battery chargers } \\
\text { Switched power supplies } \\
\text { Portable Devices } \\
\text { Household appliances }\end{array}$ & $\begin{array}{c}\text { Trains } \\
\text { Automotive } \\
\text { Aerospace }\end{array}$ & $\begin{array}{c}\text { Generation (conventional and alternative) } \\
\text { Distribution } \\
\text { Load side } \\
\text { Storage }\end{array}$ \\
\hline Benefits & $\begin{array}{c}\text { More efficient systems } \\
\text { Energy savings } \\
\text { Stability and robustness } \\
\text { Decrease size and weight } \\
\text { Integration into portable devices }\end{array}$ & $\begin{array}{l}\text { More electrical vehicles } \\
\text { More efficiency and availability } \\
\text { New power and traction systems } \\
\text { Low maintenance costs } \\
\text { Storage and regenerative systems }\end{array}$ & $\begin{array}{c}\text { More efficiency and stability } \\
\text { More integration of alternative energies } \\
\text { More grid flexibility } \\
\text { Increase reliability and robustness }\end{array}$ \\
\hline $\begin{array}{l}\text { Challenges and } \\
\text { Requirements }\end{array}$ & $\begin{array}{l}\text { Decrease losses } \\
\text { Decrease production costs } \\
\text { High reliability } \\
\text { Noise reduction }\end{array}$ & $\begin{array}{l}\text { Decrease losses, weight and size } \\
\text { Increase of power managed } \\
\text { Increase reliability }\end{array}$ & $\begin{array}{l}\text { More complexity } \\
\text { Decrease losses } \\
\text { Larger power generators } \\
\text { Larger industrial motors }\end{array}$ \\
\hline
\end{tabular}




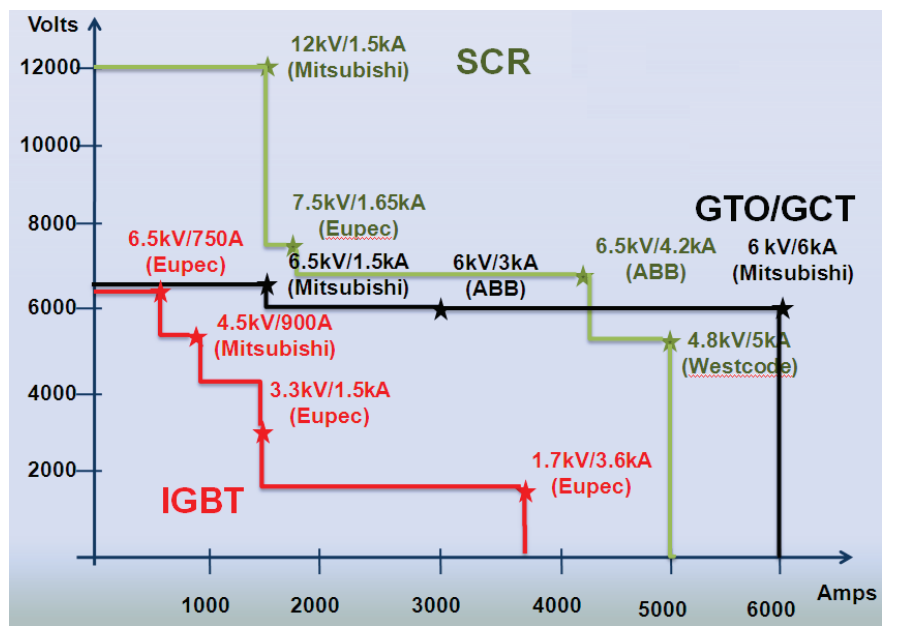

Fig. 2. Classification of the current market of power semiconductors

the multilevel converter topology with most current industrial impact [8]. A diagram of a phase of a three-level NPC is represented in Fig. 3a. The NPC topology has become a mature solution for high-power applications due to high quality of the harmonic spectra of the output waveforms, low switching losses and acceptable economical cost. Issues as the dc voltage balance control were overcome for three-level NPC and some three-level industrial products are commercialized by international companies such as $\mathrm{ABB}$, Siemens, Alstom, Tmeic-Ge, Ansaldo, Converteam, Ingeteam, Eaton, Schneider and Weg among others with power applications as pumps and fans, compressors, mine hoists, conveyors, crushers and mills, wind tunnels and marine drives.

On the other hand, the modularity (which is one of the lacks of the NPC) is an important feature of the FC topology which is formed by the series connection of basic power cells composed by a capacitor and two power semiconductors with opposite gating signals [9]. A N-level FC is formed by $\mathrm{N}-1$ power cells. A single-phase diagram of a threelevel FC is represented in Fig. 3b. In addition, the voltage balance control of the floating capacitors of the power cells can be naturally achieved by using the phase-shifted PWM modulation technique [10]. The FC topology is especially well designed for applications where the number of levels has to be high. To the authors best knowledge, only one industrial product is present in the market commercialized by Altom as the four-level VDM 6000 (up to $2240 \mathrm{~kW}$, IGBT based) [11]. It can be applied to fans and pumps, compressors, conveyors and mills, mine winding machines, propulsion drives in marine applications, as well as all sectors of the metal industry.

Finally, the multilevel CHB topology introduced in [12] also presents high modularity because it is composed by several full $\mathrm{H}$-bridges connected in series. A single-phase diagram of a five-level $\mathrm{CHB}$ is represented in Fig. 3c. A possible disadvantage of the $\mathrm{CHB}$ topology is that independent $\mathrm{dc}$ sources are needed for of each $\mathrm{H}$-bridge. For this purpose, a complex transformer with different secondaries can be used in order to build an ac-ac converter. Other possible solution is to use different dc sources to provide energy to the converter, i. e., connecting different PV strings to each $\mathrm{H}$-bridge or building a hybrid power system with fuel cells, solar panels and batteries [13]. In this way, the CHB topology has good features when several dc sources are present in the power system. Some industrial products are present in the market commercialized by Siemens, Tmeic-Ge, LS Industrial Systems, Arrowspeed, Yaskawa, Rxpe and Leader\&Harvest among others. It can be applied to retrofit, power generation, power water/wastewater, oil and gas and pulp/paper.

\section{MOdUlation TECHNIQUES FOR HIGH POWER CONVERTERS}

A very important feature of the multilevel converters operation is the modulation technique to be applied. In Fig. 4, a classification of the most common modulation techniques for multilevel converters is introduced [4]. In general, all the modulation techniques can be classified in three main groups: high switching frequency PWM, mixed switching frequency and fundamental switching frequency. The high-

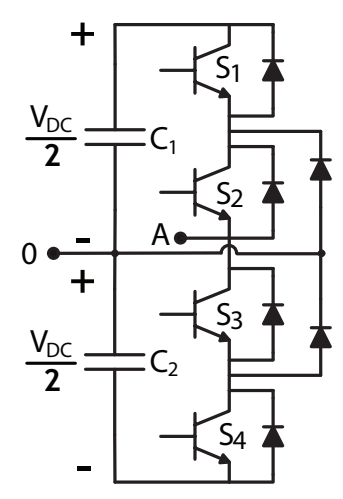

a)

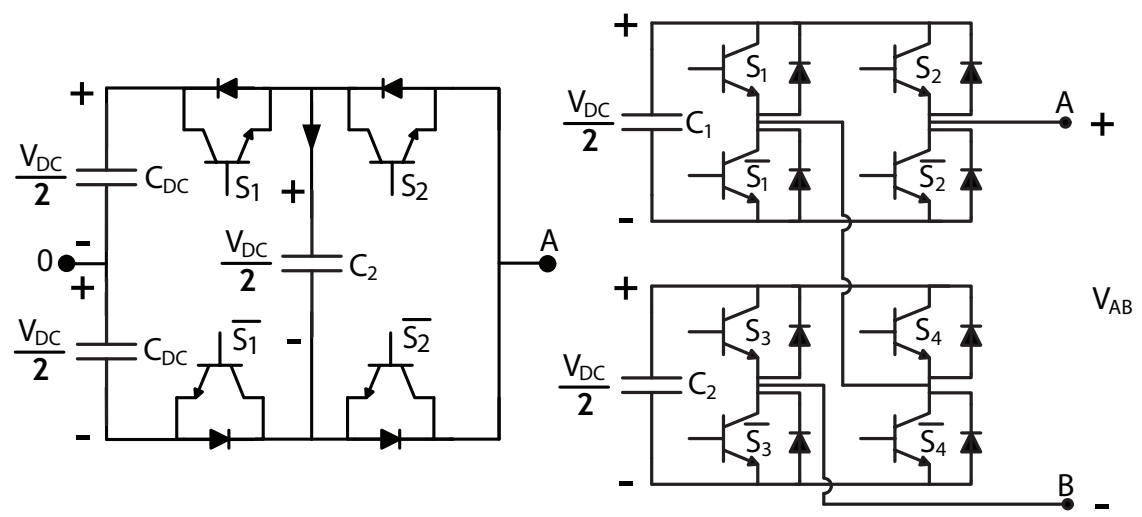

b)

c)

Fig. 3. Most common multilevel converter topologies. a) Three-level diode-clamped converter also called neutral-point-clamped converter (NPC) b) Three-level flying capacitor converter (FCC) c) Five-level cascaded H-bridge converter (CHB) 


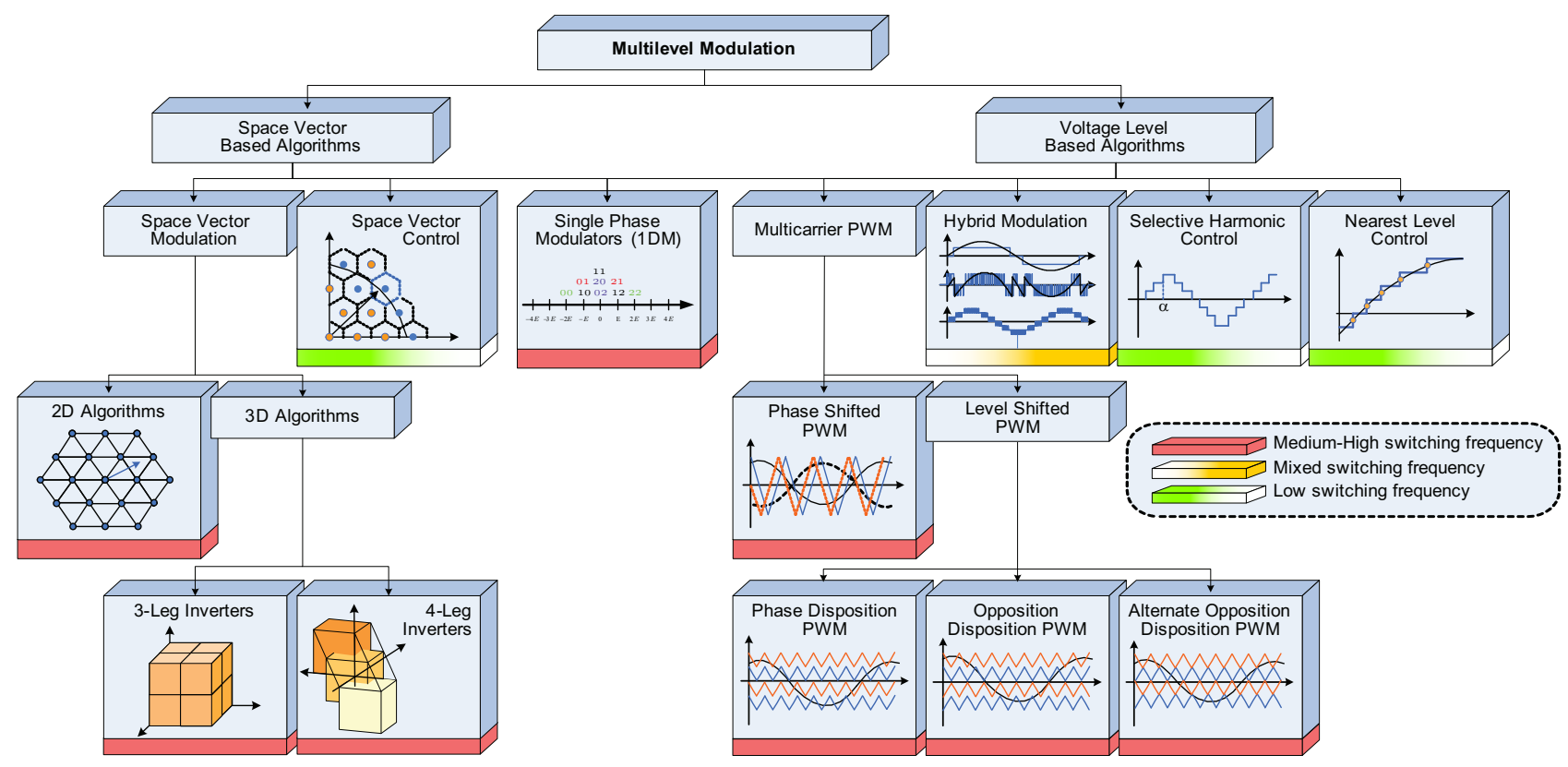

Fig. 4. Classification of the most common modulation of multilevel converters

power applications need low switching frequencies to limit the losses below acceptable values.

\section{A. Pulse Width Modulation and Space Vector Modulation Techniques}

Among the possible modulation techniques for multilevel converters, pulse width modulation (PWM) and space-vector modulation (SVM) are the most important medium-frequency modulation techniques. In the last 25 years, a large number of PWM and SVM techniques reducing the computational complexity and achieving good results have been presented [6]. PWM and SVM techniques have been compared demonstrating that both methods achieve similar high performance. Level-shifted PWM techniques are very well suited for the NPC and the phase-shifted PWM strategies are being applied to the $\mathrm{FC}$ and the $\mathrm{CHB}$.

On the other hand, space-vector modulation is a wellsuited technique to be applied to multilevel converters and is an important research focus in the last 25 years. Recently, a single-phase multilevel modulator (called 1DM) has been introduced showing its conceptual simplicity and its very low computational cost [14]. The 1DM technique can be applied to any single-phase multilevel converter and only the final trigger signals depend on the multilevel converter topology. The 1DM technique is based on the generation of the reference phase voltage as an average of the nearest voltage levels of the phase. The single-phase modulation problem is reduced to very simple calculations determining easily the switching sequence (formed by two switching states) and the corresponding switching times.

In order to briefly introduce the 1DM technique, the flow diagram to determine the switching sequence and the switching times for a phase $p$ is shown in Fig. 5 [14]. The reference

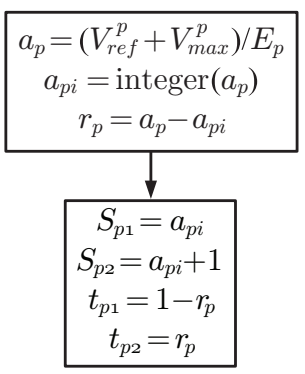

Fig. 5. Flow diagram of the generalized 1DM technique for single-phase multilevel converters

voltage of phase $p$ is defined as $V_{r e f}^{p}$ and is normalized using the dc voltage step of the phase $E_{p}$ determining the positive normalized reference voltage $a_{p} . E_{p}$ is defined as the voltage between two consecutive voltage levels assuming that it is constant. The maximum voltage that can be obtained in phase $p$ is called $V_{\text {max }}^{p}$. Using factor $a_{p}$ and its integer part $a_{p i}$, the 1DM technique easily calculates the switching sequence and the switching times. The final switching sequence of phase $p$ is formed by two switching states $S_{p 1}$ and $S_{p 2}$ with normalized switching times $t_{p 1}$ and $t_{p 2}$ respectively fulfilling that $t_{p 1}+t_{p 2}=1$. As a summary, it can be noticed that the switching sequence is always formed by two switching states equal to $a_{p i}$ and $a_{p i}+1$ with switching times $1-r_{p}$ and $r_{p}$ respectively where $r_{p}$ is determined as $a_{p}-a_{p i}$. The results of these calculations are summarized in Table II. The computational cost of the $1 \mathrm{DM}$ technique is independent of the number of levels and the necessary calculations are extremely simple.

It has been demonstrated that the 1DM method applied to each phase are equivalent with the chosen well-known multilevel space-vector modulation techniques [15]. In this 
TABLE II

SWITCHING SEQUENCE AND SWITCHING TIMES DETERMINED BY THE 1DM TECHNIQUE FOR A THREE-PHASE SYSTEM

\begin{tabular}{ccc}
\hline \hline Phase 1 & Phase 2 & Phase 3 \\
\hline$S_{11}=a_{1 i}$ & $S_{21}=a_{2 i}$ & $S_{31}=a_{3 i}$ \\
$S_{12}=a_{1 i}+1$ & $S_{22}=a_{2 i}+1$ & $S_{32}=a_{3 i}+1$ \\
$t_{11}=1-r_{1}$ & $t_{21}=1-r_{2}$ & $t_{31}=1-r_{3}$ \\
$t_{12}=r_{1}$ & $t_{22}=r_{2}$ & $t_{32}=r_{3}$ \\
\hline \hline
\end{tabular}

way, single-phase multilevel modulators can be applied to a converter with any number of levels and phases avoiding the use of conceptually and mathematically complex space-vector modulation strategies.

\section{B. Mixed Switching Frequency Modulation Techniques}

The mixed switching frequency techniques are based on a combination of very low switching frequency techniques and medium frequency PWM techniques. It is specifically designed for asymmetrical multilevel $\mathrm{CHB}$ converters where each $\mathrm{H}$ bridge provides different amount of power. The high power cells are modulated using simple comparisons with a voltage value achieving very low switching losses. The low power cells are modulated using a classical unipolar PWM technique finally generating the output waveform with low harmonic distortion and low losses [16].

\section{Low Switching Frequency Modulation Techniques}

If the power losses are still high or the multilevel converter is not an asymmetrical $\mathrm{CHB}$, a fundamental switching frequency modulation method has to be used. Two different modulation techniques are the most important methods using fundamental switching frequency: space vector control and selective harmonic control. The space vector control (SVC) is based on the space vector modulation concept but only using one switching state of the converter to generate the desired reference voltage [17]. However, it can be noticed that the SVC technique only achieves good results if the switching frequency is above $2.5 \mathrm{kHz}$ or when the number of levels of the converter is at least eleven. Therefore, only multilevel converters with a very high number of levels can use SVC for high-power applications.

Finally, the selective harmonic control methods appear as a very good option to modulate a multilevel converter for high-power applications. Among the selective harmonic control methods, the well-known selective harmonic elimination technique (SHEPWM) is a pre-programmed PWM technique where the switching angles to apply to the converter are determined in order to make zero some harmonic order in the harmonic spectrum of the output waveforms [18]. For instance, if three switching angles $\alpha_{1}, \alpha_{2}$ and $\alpha_{3}$ are considered and a symmetrical waveform is assumed, three conditions can be applied. The modulation index can be fixed generating the desired RMS voltage and two harmonic orders can be eliminated (usually $5^{\text {th }}$ and $7^{\text {th }}$ which are the lowest nontriplen harmonic orders). The SHEPWM technique has been successfully extended to different multilevel converter topologies being applied to several high-power applications.

However, current regulations all over the world do not force to make zero the harmonic content of some harmonic orders. All the grid codes which are currently coming into effect only fix maximum values for each harmonic order up to $49^{t h}$. SHEPWM technique was not originally designed taking into account these grid codes. SHEPWM achieves the elimination of several low order harmonics avoiding the necessary passive filters to reduce their contribution. However, the other harmonic orders are not considered and usually bulky and expensive filters are needed to reduce these harmonics up to acceptable levels. In order to improve the SHEPWM technique taking into account the current regulations, the selective harmonic mitigation technique (SHMPWM) was introduced in [19]. The SHMPWM is a flexible pre-programmed PWM technique where the objective is to maintain all the harmonics as much as possible below the maximum allowed values imposed by the grid codes. Therefore, is an extension of the SHEPWM technique considering the actual scenario of the regulations. In the SHMPWM technique, the switching angles $\alpha_{i}$ are determined using optimization methods where the cost function is related to the distortion that has to be reduced comparing with the grid code. The difficulty of the SHMPWM technique lies in the design of the best cost function to achieve the best results.

The SHMPWM technique has been successfully applied to three-level converters demonstrating that it can be designed for any multilevel converter topology. In [19], 15 switching angles are considered and it is shown that the SHEPWM technique is able to fix the fundamental harmonic and it eliminates harmonics up to $45^{\text {th }}$ as expected. However, harmonics $47^{\text {th }}$ and $49^{t h}$ are above the grid code that is also represented in the same figure (red line). In addition, the distortion to be reduced in harmonics $47^{\text {th }}$ and $49^{\text {th }}$ is very high so bulky and expensive filters are needed. Applying the SHMPWM technique, harmonics $47^{t h}$ and $49^{t h}$ are below the limit imposed by the grid code avoiding the use of filters. This is achieved at the expense of increasing the value of all the harmonics but all of them are below the limits acceptable for the grid code. Therefore, SHMPWM technique presents the best performance for current high power applications.

On the other hand, it should be noticed that the SHMPWM technique has been also applied to a three-level power converter with a reduced number of switching angles improving the previous results using the SHEPWM method [20]. Finally, the SHMPWM technique has been also implemented in a cascaded multilevel converter obtaining very good performance [21].

\section{Conclusions}

Power applications are step by step increasing their nominal power following the continuous power demand growth. In this paper, and the market is currently showing it, it is affirmed that multilevel converters are a very convenient way to provide power conversion for medium-voltage high-power 
applications. Challenges such as optimized modulation and control techniques, necessary hardware/software platforms and other technological issues have been overcome in the last years. In fact, the multilevel converters have currently been adopted by the industry as a mature technology and several commercial products are already present in the market.

There are still some issues to be improved such as the dissemination of the last research results (fundamental to achieve a widespread use), the high efficiency, the reliability and the fault tolerant operation where the researchers all over the world are currently focused. However, it can be affirmed that the multilevel converters have experienced a fast growing expansion with a brilliant present and future for a high number of applications as the renewable energies integration, storage systems, power distribution and motor drives.

\section{ACKNOWLEDGMENT}

The authors gratefully acknowledge the financial support provided by the Spanish Ministry of Science and Technology under the project TEC2007-61879 and by the Andalusian Government Research Council under the project P07-TIC02991.

\section{REFERENCES}

[1] B. K. Bose, "Power Electronics and Motor Drives - Recent Progress and Perspective," IEEE Trans. Ind. Electron., vol. 56, no. 2, pp. 581-588, Feb. 2009.

[2] J. M. Carrasco, L. G. Franquelo, J. T. Bialasiewicz, E. Galvan, R. Portillo, M. M. Prats, J. I. Leon and N. Moreno-Alfonso, "PowerElectronic Systems for the Grid Integration of Renewable Energy Sources: a Survey," IEEE Trans. Ind. Electron., vol. 53, no. 4, pp. 10021016, June 2006.

[3] G. Majumdar, "Recent Technologies and Trends of Power Devices," in International Workshop on Physics of Semiconductor Devices, Mumbai (India), Dec. 2007.

[4] L. G. Franquelo, J. Rodriguez, J. I. Leon, S. Kouro, R. Portillo and M. M. Prats, "The age of multilevel converters arrives," IEEE Trans. Ind. Electron. Magazine, vol. 2, no. 2, pp. 28-39, June 2008.

[5] J. Rodriguez, S. Bernet, B. Wu, J. O. Pontt and S. Kouro, "Multilevel Voltage-Source-Converter Topologies for Industrial Medium-Voltage Drives," IEEE Trans. Ind. Electron., vol. 54, no. 6, pp. 2930-2945, Dec. 2007.

[6] J. Rodriguez, L. G. Franquelo, S. Kouro, J. I. Leon, R. Portillo, M. M Prats and M. A. Perez, "Multilevel Converters: An Enabling Technology for High-Power Applications," Proceedings of the IEEE, vol. 97, no. 11 pp. 1786-1817, Nov. 2009.
[7] S. Kouro, M. Malinowski, K. Gopakumar, L. G. Franquelo, J. Pou, J. Rodriguez, B. Wu, M. A. Perez and J. I. Leon, "Recent Advances and Industrial Applications of Multilevel Converters," IEEE Trans. Ind. Electron., vol. 57, no. 8, Aug. 2010.

[8] A. Nabae, I. Takahashi and H. Akagi, "A neutral-point clamped PWM inverter," IEEE Trans. Ind. Applicat., vol. 1A-17, no. 5, pp. 518-523, Sep.-Oct. 1981.

[9] T. A. Meynard and H. Foch, "Multilevel Voltage-Source-Converter Topologies for Industrial Medium-Voltage Drives," in Proc. European Conference on Power Electronics and Applications, vol. 2, pp. 45-50, 1992.

[10] R. H. Wilkinson, T. A. Meynard and H. T. Mouton, "Natural Balance of Multicell Converters: The General Case," IEEE Trans. Power Electron., vol. 21 , no. 6, pp. 1658-1666, Nov. 2006.

[11] ALSTOM, "Air Cooled Medium Voltage AC Drives ALSPA VDM6000," [Online]. Available: http:// www.alstom.com.

[12] M. Marchesoni, M. Mazzucchelli and S. Tenconi, "A nonconventional power converter for plasma stabilization," IEEE Trans. Power Electron., vol. 5, pp. 212-219, 1991.

[13] Feel-Soon Kang, Sung-Jun Park, Su Eog Cho, Cheul-U Kim and T Ise, "Multilevel PWM inverters suitable for the use of stand-alone photovoltaic power systems," IEEE Trans. Energy Conversion, vol. 20, no. 4, pp. 906-915, Dec. 2005.

[14] J. I. Leon, R. Portillo, S. Vazquez, J. J. Padilla, L. G. Franquelo and J. M. Carrasco, "Simple Unified Approach to Develop a Time Domain Modulation Strategy for Single-Phase Multilevel Converters," IEEE Trans. Ind. Electron., vol. 55, no. 9, pp. 3239-3248, Sept. 2008.

[15] J. I. Leon, S. Vazquez, J. A. Sanchez, R. Portillo, L. G. Franquelo, J. M. Carrasco and E. Dominguez, "Conventional Space-Vector Modulation Techniques Versus the Single-Phase Modulator for Multilevel Converters," IEEE Trans. Ind. Electron., vol. 57, no. 7, pp. 2473-2482, July 2010.

[16] C. Rech and J. R. Pinheiro, "Hybrid multilevel converters: Unified analysis and design considerations," IEEE Trans. Ind. Electron., vol. 54, no. 2, pp. 1092-1104, Apr. 2007.

[17] J. Rodríguez, L. Morán, P. Correa and C. Silva, "A vector control technique for medium-voltage multilevel inverters," IEEE Trans. Ind. Electron., vol. 49, no. 4, pp. 882-888, Aug. 2002.

[18] H. S. Patel and R. G. Hoft, "Generalized techniques of harmonic elimination and voltage control in thyristor inverters-Part 1: Harmonic elimination," IEEE Trans. Ind. Applicat., vol. IA-9, pp. 310-317, May/June 1973.

[19] L. G. Franquelo, J. Nápoles, R. Portillo, J. I. Leon and M. A. Aguirre, “A flexible Selective Harmonic Mitigation Technique to Meet Grid Codes in Three-level PWM Converters," IEEE Trans. Ind. Electron., vol. 54, no. 6, pp. 3022-3029, Dec. 2007.

[20] J. Nápoles, J. I. Leon, R. Portillo, L. G. Franquelo and M. A. Aguirre, "Selective Harmonic Mitigation Technique for High-Power Converters," IEEE Trans. Ind. Electron., vol. 57, no. 7, pp. 2315-2323, Aug. 2010.

[21] J. Nápoles, J. I. Leon, L. G. Franquelo, R. Portillo and M. A. Aguirre, "Selective harmonic mitigation technique for multilevel cascaded $\mathrm{H}$ bridge converters," IEEE 35th Annual Conference of the Industrial Electronics Society (IECON'09), pp. 806-811, Nov. 2009, Porto (Portugal). 